NASA Technical Memorandum 88978

\title{
Nondestructive Evaluation of Structural Ceramics
}

\author{
(NASA-TM-88978) NCNDESTROCTIVE EVALUATION \\ OP STROCTURAL CERAMICS (NASA) 23 P CSCL 14D
}

N 87-18109

Unclas

G3/38 43530

Stanley J. Klima

Lewis Research Center

Cleveland, Ohio

George Y. Baaklini

Cleveland State University

Cleveland, Ohio

and

Phillip B. Abel

Lewis Research Center

Cleveland, Ohio

Prepared for the

Twenty-fourth Automotive Technology Development

Contractors' Coordination Meeting

sponsored by the U.S. Department of Energy

Dearborn, Michigan, October 27-30, 1986

\section{Nusn}


NONDESTRUCTIVE EVALUATION OF STRUCTURAL CERAMICS

\author{
Stanley J. Klima \\ National Aeronautics and Space Administration \\ Lewis Research Center \\ Cleveland, Ohio 44135 \\ George Y. Baaklini \\ Cleveland State University \\ Cleveland, ohio 44115 \\ and \\ Phtllip B. Abel \\ National Aeronautics and Space Administration \\ Lewis Research Center \\ Cleveland, Ohio 44135
}

\begin{abstract}
SUMMARY
A review is presented on research and development of techniques for nondestructive evaluation and characterization of advanced ceramics for heat engine applications. Highlighted in this review are Lewis Research Center efforts in microfocus radiography, scanning laser acoustic microscopy (SLAM), scanning acoustic microscopy (SAM), scanning electron acoustic microscopy (SEAM), and photoacoustic microscopy (PAM). The techniques were evaluated by applying them to research samples of green and sintered silicon nitride and silicon carbide in the form of modulus-of-rupture bars containing seeded voids. Probabilities of detection of voids were determined for diameters as small as $20 \mu \mathrm{m}$ for microfocus radiography, SLAM, and SAM. Strengths and limitations of the techniques for ceramic applications are identified. The application of ultrasonics for characterizing ceramic microstructures is also discussed.
\end{abstract}

\title{
INTROOUCTION
}

The need for quantitative assessment of the reliability of flaw detection techniques arises from the application of fracture mechanics principles to the design of critical parts. The fracture mechanics concept assumes flaws are present in all materials and quantitatively describes their effect on structural integrity. Thus, a critical crack size that would result in unstable crack growth can be defined for any combination of material and loading conditions (ref. 1). For simple components such as pressure vessels, fracture control can be achieved by proof testing to a pressure which exceeds the operating stress. If the vessel does not fracture, the absence of critical flaws is assured. For complex structures however, proof testing logic may not be applicable because in many cases it is not possible to duplicate precisely the nature of operating stresses. Therefore, structural integrity of complex components must be established by a different approach, the most practical of which may be nondestructive evaluation (NDE). The role of NDE would be to screen out parts containing flaws equal to or greater than the critical crack size before they are put into service (ref. 2). In some applications it may 
be necessary to ensure that flaws significantly smaller than critical size are absent if subcritical crack growth due to such things as stress-corrosion or fatigue is to be avoided.

The use of fracture mechanics concepts in ceramic component design places a premium on the ability of nondestructive inspection to detect small defects (refs. 3 and 4 ), and on the need to determine the practical reliability of an NDE procedure when that procedure is considered for detection of flaws of a specific type and size (ref. 5). Such information is essential if the designer is to rely on NDE to assure that components are free of flaws that exceed a specified size in the material chosen for a particular service environment. If the design is such that the critical crack size is greater than the smallest flaw that can be reliably detected (or the largest flaw that will be missed a significant proportion of the time) then the inspection process can be used. The difference between the smallest detectable flaw and the critical crack size can be regarded as a measure of the margin of safety.

The reliablitity of various conventional nondestructive techniques for detection of cracks in metallic aircraft engine components was reported in reference 6 . The only previously reported work on NDE detection reliablitity for flaws in heat engine ceramics is presented in references 7 to 10 . This paper examines some of the factors that influence the detectability of minute flaws in ceramics, and focuses attention on requirements for assuring adequate detection sensitivity and reliability with radiographic and acoustic microscropy techniques. The paper also discusses the applicability of thermoacoustic techniques for ceramic applications and a program for characterizing ceramic microstructures through ultrasonic measurements.

\section{RELIABILITY OF FLAW DETECTION \\ Specimen Preparation}

Figure 1 shows a flow chart which describes the preparation of specimens containing seeded voids. The SIC starting powder contained sintering aids and binder material (boron and carbonaceous resins). The $\mathrm{Si}_{3} \mathrm{~N}_{4}$ starting powder contained 6 percent $\mathrm{Y}_{2} \mathrm{O}_{3}$ and 6 percent $\mathrm{SiO}_{2}$ to promote densification during sintering. For surface voids, all of the powder necessary to make up the specimen thickness was poured into the die and the microspheres were pressed into the top surface. For internal voids the amount of powder put in the die before and after placement of the microspheres was controlled to achieve the desired void depth in the finished specimen. The die pressed bars were vacuum sealed in latex tubing and cold isopressed to approximately 60 percent of full density. After removing the latex the compacts were heated in vacuum to vaporize the plastic microspheres. The as-sintered density of silicon carbide ranged from 94 to 97 percent of full theoretical density while for silicon nitride it was more than 98 percent of theoretical. As-fired test bars measured nominally $28 \mathrm{~mm}$ long, $7 \mathrm{~mm}$ wide, and 2 to $4 \mathrm{~mm}$ thick, as required for NDE reliability determinations. After NOE, internal volds were exposed by diamond grinding and measured by optical and electron microscopy. These data are iisted in table 1 . The dimensions of voids in green compacts were assumed to be equivalent to the seeded spheres. A complete description of specimen fabrication and void characterization is given in reference 10. 
NDE Techniques and Statistical Analysis

The reliability of microfocus radiography and scanning laser acoustic microscopy (SLAM) for detection of seeded voids was evaluated over a wide range of void diameters and depths. Probability of detection data was obtained for scanning acoustic microscopy (SAM) at a single void diameter and depth. Brief descriptions of the NDE techniques and the procedure used to statistically analyze flaw detection data follow. Detalled descriptions are given in references 7 to 11 .

Microfocus $x$-ray. - The x-ray system (fig. 2) was operated in the 30 to $60 \mathrm{kV}$ range with a moiybdenum anode which produced photon energy levels between 17 and $20 \mathrm{keV}$. Higher photon energy levels were found to result in reduced film contrast which is undesirable. Radiographic film images at a magnification of 2.5 were made by the projection method and examined with the aid of a $7 X$ optical magnifier.

SLAM. - The SLAM technique is illustrated in figure 3. 100 MHz ultrasonic waves transmitted through the specimen are modulated by material surface and internal characteristics. The relative intensity and phase of the waves reaching the reflective $\mathrm{film}$ on the cover silp are detected by a laser beam raster scanned over an area approximately $2 \mathrm{~mm}$ square. The beam is reflected into a photodetector and converted to an electronic signal. Thus, an image of the acoustic perturbations caused by features such as cracks, voids, density variations, etc., are displayed in real time on a video monitor at a magnification of nearly $100 x$.

SAM. - The SAM technique uses a single transducer to generate and receive ultrasonic energy (fig. 4). Good sensitivity and resolution are achieved by focussing moderately high frequency ultrasonic energy ( 30 to $100 \mathrm{MHz}$ ) on a small spot, raster scanning the lens with respect to the sample, and time-gate sampling the reflected ultrasonic pulse amplitude. Any features that produce an acoustic impedance mismatch within the sample or a change in acoustic impedance at the specimen surface can cause detectible variations in the digitized and stored spatial map of reflected signal amplitude. If a flaw is larger than the focal spot, some degree of flaw slzing can be achieved. Flaws smaller than the focal spot can be detected but if two or more are located a wavelength or less apart they cannot be resolved.

\section{Statistical Analysis}

Due to uncertainties associated with equipment, operator, flaw characteristics, etc., the detection of flaws in engineering materials and components is probabilistic in nature and must be evaluated using a statistical approach. Since an attempt at detection of a given flaw can have only two possible outcomes (it is either detected or missed) the probability of detection (POD) can be described by the binomial distribution. The flaws were grouped into size intervals because fabrication variables precluded making large numbers of voids in a wide range of discrete sizes. The probability of detection was calculated for each interval by the "optimized probability" method described in reference 5. A Fortran computer program that calculates and plots NDE reliability data is listed in reference 7 (NASA TM version) 
NOE reliability data for the microfocus $x$-ray technique is presented in figures 5 and 6 in the form of plots of probability of detection versus void size expressed as percent of total specimen thickness. As shown in table I, the internal void diameters ranged from 50 to $528 \mathrm{\mu m}$ in the green specimens and 20 to $477 \mu \mathrm{m}$ in the fully densified bars.

All of the POD curves are characterized by a sharp drop in probability of detection in a region below approximately 2.5 percent thickness sensitivity. Figure 5(a) shows that the detection sensitivity of internal voids in green silicon nitride is nearly the same as in green silicon carbide, approximately 2.5 percent at a POD of 90 percent. The curves in figures $5(b)$ and $(c)$ are more revealing, showing that surface voids are more easily detected than internal voids for both materials. Analysis of a limited number of internal voids in green compacts revealed they were partially filled with loose powder, which has the effect of reducing contrast on the $x$-ray film. This could account for the lower apparent sensitivity. In naturally occurring voids this may be less of a problem because they are not usually produced by vaporizing a supporting material such as the seeded spheres used in this investigation. For green materials, therefore, the POD data presented here for surface voids would probably apply to naturally occurring internal voids regardless of the fabrication technique used to make the specimens or parts.

For sintered materials, the data in figure 6 show many interesting features. For example figure $6(a)$ indicates unusually good sensitivity to internal voids in silicon nitride. However, chemical analysis of void walls, reported in reference 10, proved that detection of some internal voids in silicon nitride was influenced by a deposit of yttrium, a strong absorber of $x$-rays. Thus, some of the volds appeared to have a high density shell on the radiograph, resulting in enhanced detectability. This condition could occur in any sintered material that utilizes sintering aids composed of heavy elements. The enhanced detectability phenomenon was not observed with voids seeded in slificon carbide (fig. 6(b)), which did not contain similar sintering aids.

NDE reliablitty data for SLAM is presented in figures 7 and 8 . Figure 7 which contains data for surface connected voids only, shows the effect of surface condition and specimen thickness on detectability of flaws. From the POD curves for as-fired specimens, it is evident that 0.90 probability of detection at 0.95 confidence level was not attained for any thickness up to 4 $\mathrm{mm}$. However, when the same specimens were lightly polished to a surface finish of nominally $2 \mu \mathrm{m}$, the POD was significantly improved. POD of 0.90 was achieved for all specimen thicknesses. Thus, it appears that as-fired surfaces cause a background noise level higher than can be tolerated for nondestructive detection of minute defects by SLAM. The measured surface finish of as-fired samples was $8 \mu \mathrm{m}$ (peak-to-valley) but it should be noted that topography was the only surface characteristic that was measured. It is possible that other factors such as fine near-surface porosity, acting as ultrasonic wave scatterers, could have contributed to the generally low POD for as-fired samples.

Figure 8 shows a plot which summarizes SLAM POD data obtained for internal volds in specimens with diamond-ground surfaces (ref. 9). The boundaries 
of the bar graphs indicate the minimum void sizes and maximum depths (from the laser-scanned surface) at which $0.90 / 0.95$ P0D/confidence-level was achieved. As expected, there is a significant effect of void size and depth. However, the plot also shows that $0.90 / 0.95$ is obtained at greater depths and smaller void sizes in silicon nitride than in silicon carbide. This is probably due to differences in microstructure between the two materiais. The grain size in silicon carbide was an order of magnitude greater than in silicon nitride. The bulk porosity in silicon carbide was also higher than in silicon nitride. Both of these conditions would have the effect of increasing uitrasonic scatter and reducing the POD of volds in silicon carbide relative to silicon nitride.

Also shown in figure $B$ is a single data point representing preliminary results obtained with the SAM technique. Voids at only a single diameter (nominally $20 \mu \mathrm{m}$ ) situated $1 \mathrm{~mm}$ from the scanned surface were available at the time of the SAM evaluation. All of 38 voids were detected in silicon nitride samples, yielding a POD better than $0.90 / 0.95$ for this very small void size at a depth of about 50 times the diameter. The method needs to be evaluated for a greater range of depths, materials, and microstructures but promises to be an extremely useful technique for scanning critical areas of heat engine components.

\section{THERMOACOUSTIC TECHNIQUES}

Thermoacoustic techniques can be applied to ceramics in either a noncontacting mode similar to $x$-ray methods, or a contacting mode as in ultrasonics. The technique essentially measures relative differences in surface and nearsurface thermal properties of the material being evaluated. The absorption of intensity modulated electromagnetic radiation focused at any point on the sample gives rise to localized cyclic heating and cooling which in turn generates elastic waves at the modulation frequency. The amplitude and phase of these waves can be measured at another point on the specimen surface by a piezoelectric crystal in contact with the specimen, or in the surrounding medium by a noncontacting method using a sensitive microphone or a laser. An overview of the theoretical and experimental aspects of the thermoacoustic techniques is presented in reference 12.

SEAM. - A schematic diagram of the scanning electron acoustic microscopy technique (SEAM), which utilizes a scanning electron beam heating source and a contact piezo-electric acoustic sensor housed in a scanning electron microscrope enclosure, is shown in figure 9 . The thermal diffusivity of the volume of material containing the flaw differs from that of the matrix material. Thus, the elastic waves produced as the intensity modulated electron beam passes over the flaw differ in amplitude and/or phase from the surrounding material. Modulation frequencies can range from $100 \mathrm{~Hz}$ to $10 \mathrm{kHz}$, the lower frequencies achieving greater penetration. A thermoacoustic image of a raster-scanned area can be produced, an example of which is shown in figure 10. The SEM backscatter image shows a portion of a crack that originates at the edge of a silicon carbide modulus of rupture bar, as well as dust particles on the specimen surface. The SEAM image clearly shows the subsurface extension of the crack as well as the portion seen on the SEM image. Note, however, that the surface dust did not register on the SEAM image. 
Preliminary investigation of the SEAM technique in the laboratory using silicon carbide and silicon nitride samples containing defects artificially induced at predetermined locations resulted in the following observations: (1) surface features such as pits and nodules were detected and imaged; (2) cracks produced naturally by processing, and tight cracks produced by knoop indentations were imaged; (3) seeded subsurface voids up to $100 \mu \mathrm{m}$ below the interrogating surface were imaged, while voids at a depth of $300 \mu \mathrm{m}$ were missed. Reliability of detection data were not obtained for the SEAM technique. Calculations show that resolution less than $10 \mu \mathrm{m}$ appears to be attainable. The scan rate was quite fast, with a scan time of $125 \mathrm{sec}$ for a 256 line image of an area 4 by $5 \mathrm{~mm}$. Although the SEAM technique has good sensitivity and resolution capability, the need to perform the scan in a vacuum is a disadvantage. In addition, since structural ceramics are relatively poor electrical conductors, a coating is necessary to attain the stated sensitivity and resolution. Therefore, the SEAM technique is best suited for laboratory material evaluation and does not appear promising for practical inspection of heat engine components.

PAM. - A block diagram of a photoacoustic microscopy (PAM) system is shown in figure 11. The sample to be evaluated is placed inside an isolation cell containing a sensitive microphone and a minimal volume of gas, usually air. The sample is 11 luminated through a clear window by a chopped laser beam focused onto the sample surface. Light absorbed by the sample is converted in part into heat, resulting in periodic heat flow from the sample to the surrounding gas. The resultant pressure fluctuations produced by a cyclic heating and cooling of the specimen and the gas in the immediate vicinity of the specimen are transmitted by the bulk gas medium to the microphone. The magnitude and phase of the acoustic signal is directly related to the thermal properties of the sample and the surrounding medium, the chopping frequency, and the cell design. The acoustic frequency coincides with the chopping frequency. The depth of material that can be evaluated depends on the wavelength of the incident light, the absorption coefficient of the sample, and the thermal diffusion length. Generally, the depth of material that can be evaluated is of the order of one or two thermal diffusion lengths. Thus, like the SEAM technique PAM is limited to specimen surface and near-surface evaluation.

Extensive investigation of the PAM technique resulted in the the following observations obtained with sintered silicon nitride samples: (1) surface connected pores and inclusions $25 \mathrm{\mu m}$ and larger were detected; (2) subsurface voids and inclusions $35 \mu \mathrm{m}$ and larger were detected up to $70 \mu \mathrm{m}$ below the interrogating surface, but voids $200 \mu \mathrm{m}$ diameter and $200 \mu \mathrm{m}$ deep were missed; (3) background noise level was high, indicating extreme sensitivity to material variations other than discrete flaws; (4) the method was time consuming, requiring over $4 \mathrm{hr}$ to scan an area $1 \mathrm{~cm}$ on a side with a resolution of $25 \mu \mathrm{m}$.

When applied to silicon nitride samples in the green state the technique was sensitive to surface imperfections and texture variations but did not detect near surface anomalies, including side drilled holes up to $250 \mu \mathrm{m}$ diameter. Background noise level produced with the green samples was very high, making detection of even relatively large flaws difficult. Optical examination of the region scanned by the laser revealed an altered surface apparently caused by emission of material from the specimen surface. Some of 
the emitted material coated the cell window, cutting down on transmission of light. Subsequent sintering of these samples produced a large number of surface cracks in the laser scanned regions that did not occur in the unscanned zones. Because of the apparent damage done to the specimen surface the PAM technique does not appear to be an attractive alternative for examination of green ceramics, in spite of the fact that it can be used in the noncontacting mode.

\section{ULTRASONIC MICROSTRUCTURAL CHARACTERIZATION}

It was previously shown that ultrasonic velocity and attenuation measurements can be used to measure bulk density variations (refs. 13 and 14) and to assess material strength to the extent that it is controlled by microstructure. This application of ultrasonics is being explored in greater depth at NASA Lewis as outlined by the flow chart in figure 12. Sintered silicon carbide MOR bars with controlled densities and microstructures have been prepared in-house by varying the powder grinding, pressing, and sintering conditions, and by hot isostatic pressing. Surface finish is another variable that will be studied. After inspection by established NDE methods, the bars will be characterized by specially developed high frequency ultrasonic techniques. Available frequencies range from $20 \mathrm{MHz}$ to as high as $1 \mathrm{GHz}$. After ultrasonic characterization the specimens will be fractured in four-point bending. Correlations between microstructure, bulk density, surface condition, and strength will then be determined.

\section{CONCLUDING REMARKS}

Reliability of void detection in ceramics by microfocus radiography was affected by various material and process related parameters. It was observed that photon energy levels less than $20 \mathrm{keV}$ produced better radiographic contrast and hence better void detectability than higher energy levels. Migration of yttrium to the region surrounding void walls enhanced the detectability of voids in many, but not all sintered silicon nitride specimens. The sensitivity of $x$-rays to volds in green silicon carbide and silicon nitride compacts was reduced by the presence of loose powder inside the cavity.

Reliability of void detection by scanning laser acoustic microscopy was affected by a different set of parameters. The larger grain size and higher relative porosity in sintered silicon carbide resulted in significantiy reduced detection capability than was observed for silicon nitride. Void detection in both materials was greatly improved when the as-sintered surface was removed by surface grinding or polishing. Scanning acoustic microscopy utilizing ultrasonic frequencies between 30 and $100 \mathrm{MHz}$ promises to be useful for scanning critical areas on ceramic heat engine components. Preliminary data indicate that voids $20 \mu \mathrm{m}$ diameter and $1 \mathrm{~mm}$ deep can be reliably detected. These voids were significantly smaller and deeper than the smallest voids detected with equal rellability by SLAM and radiographic methods.

Thermoacoustic imaging techniques were investigated to determine applicability to simple ceramic test bars. Scanning electron acoustic microscopy proved to be useful for detecting tight surface cracks and pits and near surface voids less than $100 \mu \mathrm{m}$ in diameter and $100 \mu \mathrm{m}$ deep with good 
resolution. However, the need to conduct the examination in a SEM enclosure and to coat the specimen with a conductive material limits the SEAM method to the laboratory. The photoacoustic microscopy method was evaluated on both green and sintered specimens. The PAM method was capable of detecting surface pits down to $25 \mu \mathrm{m}$ and near-surface voids down to $35 \mu \mathrm{m}$ diameter. As with the SEAM technique, detection was limited to within $100 \mu \mathrm{m}$ of the surface. The PAM method was not useful for green ceramic compacts because laser scanning apparently caused surface cracking to occur when the specimens were subsequently sintered. In either case (sintered or green materials) the method is time consuming, which makes it unattractive for scanning large areas.

\section{REFERENCES}

1. Kanninen, M.F.; and Popelar, C.H.: Advanced Fracture Mechanics. Oxford University Press, 1985.

2. Packman, P.F.: Fracture Toughness and NDT Requirements for Aircraft Design. Nondestr. Test. (Guildford, Engl.), vol. 6, no. 6, Dec. 1973, pp. 314-324.

3. Bradt, R.C.; Hasselman, D.P.H.; and Lange, F.F.; eds.: Fracture Mechanics of Ceramics. Plenum Press, vols. 1-2, 1974, vols. 3-4, 1978.

4. Rice, R.W., et al.: Failure Causing Defects in Ceramics; What NDE Should Find. NRL-MR-4075, Naval Research Lab., Oct. 1979.

(Ava11. NTIS, AD-A078234).

5. Packman, P.F., et al.: Rellability of Flaw Detection by Nondestructive Inspection. Metals Handbook, Vo1. 11, 8th ed. H.E. Boyer, ed., American Society for Metals, Metals Park, OH, 1976, pp. 414-424.

6. Rumme1, W.D., et a 1.: Reliability of Nondestructive Inspection (NDI) of Aircraft Engine Components. SAALC/MM-8151, San Antonio Air Logistics Command, Jan. 1984. (Ava11. NTIS, AD-A155320).

7. Roth, D.J., et a1.: Reliability of Void Detection in Structural Ceramics by use of Scanning Laser Acoustic Microscopy. Mater. Eval., vol. 44, no. 6. May 1986, pp. 762-769, 761 .

8 Baaklini, G.Y.; Kiser, J.D.; and Roth, D.J.: Radiographic Detectabllity Limits for Seeded Voids in Sintered Silicon Carbide and silicon Nitride. Adv. Ceram. Mater., vol. 1, no. 1, Jan. 1986, pp. 43-49.

9 Roth, D.J.; and Baaklini, G.Y.: Reliability of Scanning Laser Acoustic Microscopy for Detecting Internal Voids in Structural Ceramics. Adv. Ceram. Mater., vol. 1, no. 3, July, 1986, pp. 252-258.

10. Baaklini, G.Y.; and Roth, D.J.: Probability of Detection of Internal Voids in Structural Ceramics Using Microfocus Radiography. J. Mater. Res., vol. 1, no. 3, May-June 1986, pp. 457-467. 
11. Nikoonahad, M.: Reflection Acoustic Microscopy for Industrial NDE. Research Techniques in Nondestructive Testing, vol. 7, Academic Press, 1984, pp. 217-257.

12. Rosencwaig, A.: Photoacoustics and Photoacoustic Spectroscopy. John Wiley a Sons, 1980.

13. Klima, S.J.: NDE of Advanced Ceramics. Mater. Eval., vol. 44, no. 5, Apr., 1986, pp. 571-576.

14. Klima, S.J., et al.: Ultrasonic Velocity for Estimating Density of Structural Ceramics. NASA TM-82765, 1981. 
TABLE I. - DIMENSIONS OF SEEDED INTERNAL VOIDS. GEOMETRY SIMILAR TO AN OBLATE SPHEROID, WITH AXIS IN THE DIRECTION OF SPECIMEN THICKNESS

\begin{tabular}{|c|c|c|c|c|c|c|}
\hline \multirow[t]{3}{*}{ Material } & \multirow{3}{*}{$\begin{array}{c}\text { Original } \\
\text { sphere } \\
\text { diameter, } \\
\mu \mathrm{m}\end{array}$} & \multirow{3}{*}{$\begin{array}{l}\text { Number of } \\
\text { spheres } \\
\text { seeded }\end{array}$} & \multicolumn{4}{|c|}{ Dimensions after sintering } \\
\hline & & & \multicolumn{2}{|c|}{ Axis, $\mu \mathrm{m}$} & \multicolumn{2}{|c|}{ Diameter, $\mu \mathrm{m}$} \\
\hline & & & Mean & $\begin{array}{l}\text { Standard } \\
\text { deviation }\end{array}$ & Mean & $\begin{array}{l}\text { Standard } \\
\text { deviation }\end{array}$ \\
\hline $\mathrm{Si}_{3} \mathrm{~N}_{4}$ & $\begin{array}{r}80 \\
115 \\
200 \\
321 \\
528\end{array}$ & $\begin{array}{l}69 \\
39 \\
31 \\
28 \\
21\end{array}$ & $\begin{array}{r}20 \\
37 \\
133 \\
233 \\
307\end{array}$ & $\begin{array}{r}4 \\
5 \\
17 \\
16 \\
14\end{array}$ & $\begin{array}{r}25 \\
68 \\
139 \\
267 \\
386\end{array}$ & $\begin{array}{r}6 \\
5 \\
8 \\
18 \\
15\end{array}$ \\
\hline $\mathrm{SiC}$ & $\begin{array}{r}50 \\
80 \\
115 \\
200 \\
321 \\
528\end{array}$ & $\begin{array}{l}50 \\
47 \\
68 \\
19 \\
39 \\
43\end{array}$ & $\begin{array}{r}32 \\
59 \\
77 \\
165 \\
297 \\
477\end{array}$ & $\begin{array}{r}3 \\
6 \\
10 \\
29 \\
19 \\
47\end{array}$ & $\begin{array}{r}58 \\
100 \\
131 \\
194 \\
307 \\
505\end{array}$ & $\begin{array}{r}3 \\
8 \\
8 \\
11 \\
15 \\
28\end{array}$ \\
\hline
\end{tabular}




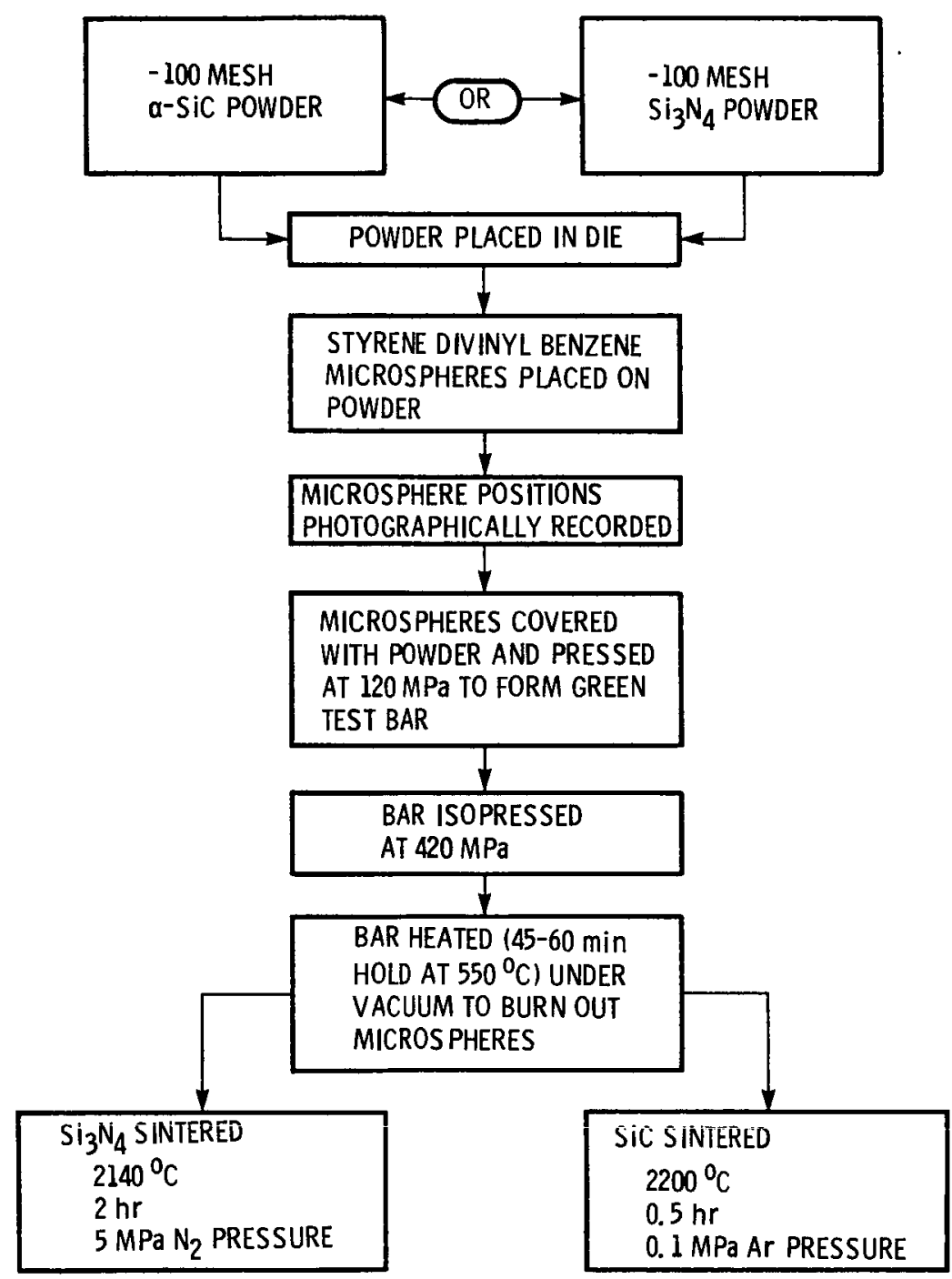

Figure 1. - Fabrication of silicon nitride and silicon carbide test specimens with seeded internal voids. 


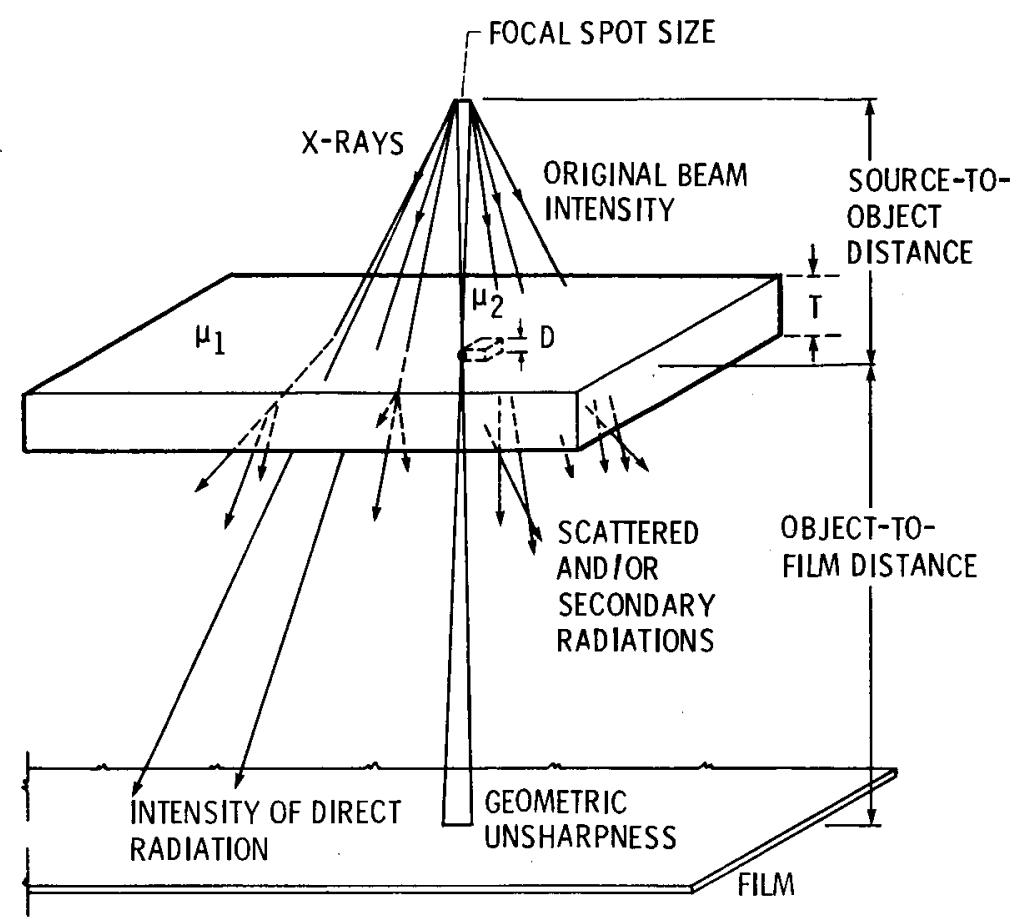

Figure 2. - Schematic configuration of microfocus projection radiography, where $D$ is thickness of defect, $T$ is thickness of sample, $\mu_{1}$ is attenuation coefficient of the object, and $\mu_{2}$ is attenuation coefficient of the defect.

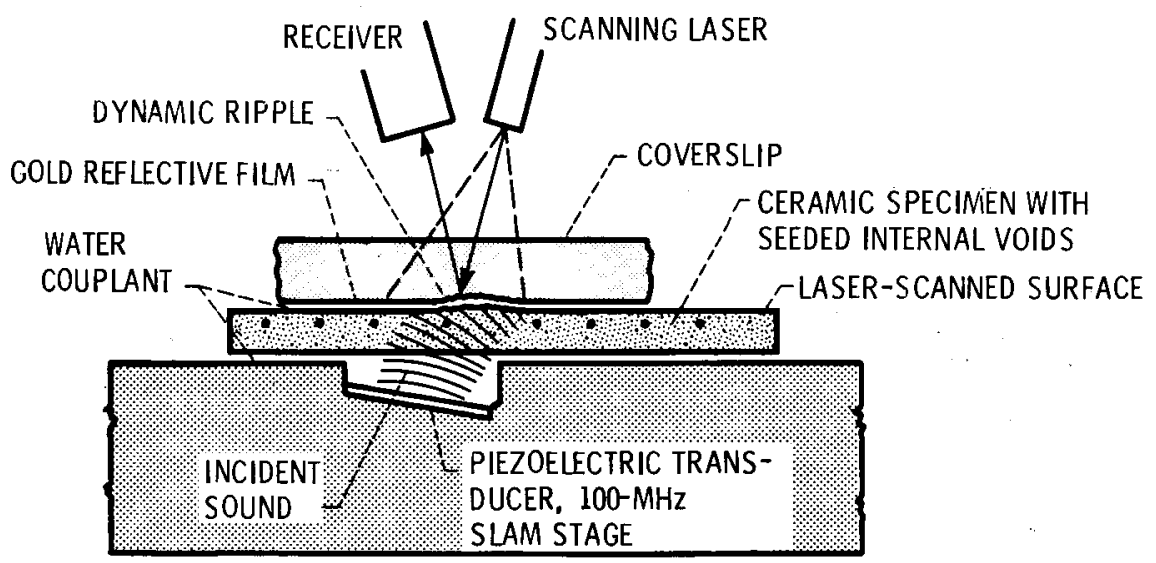

Figure 3. - Scanning laser acoustic microscopy (SLAM) of ceramic test bars containing seeded internal defects. 


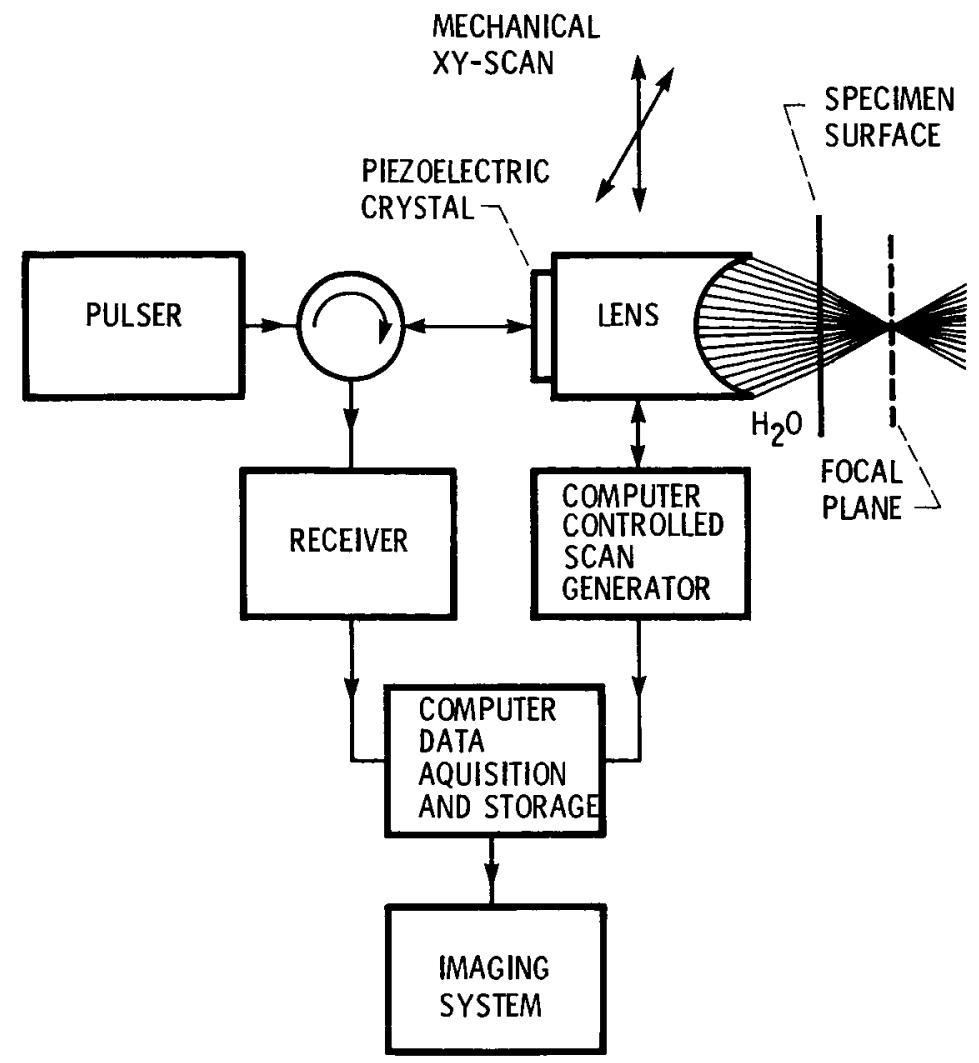

Figure 4. - Scanning acoustic microscope (SAM).
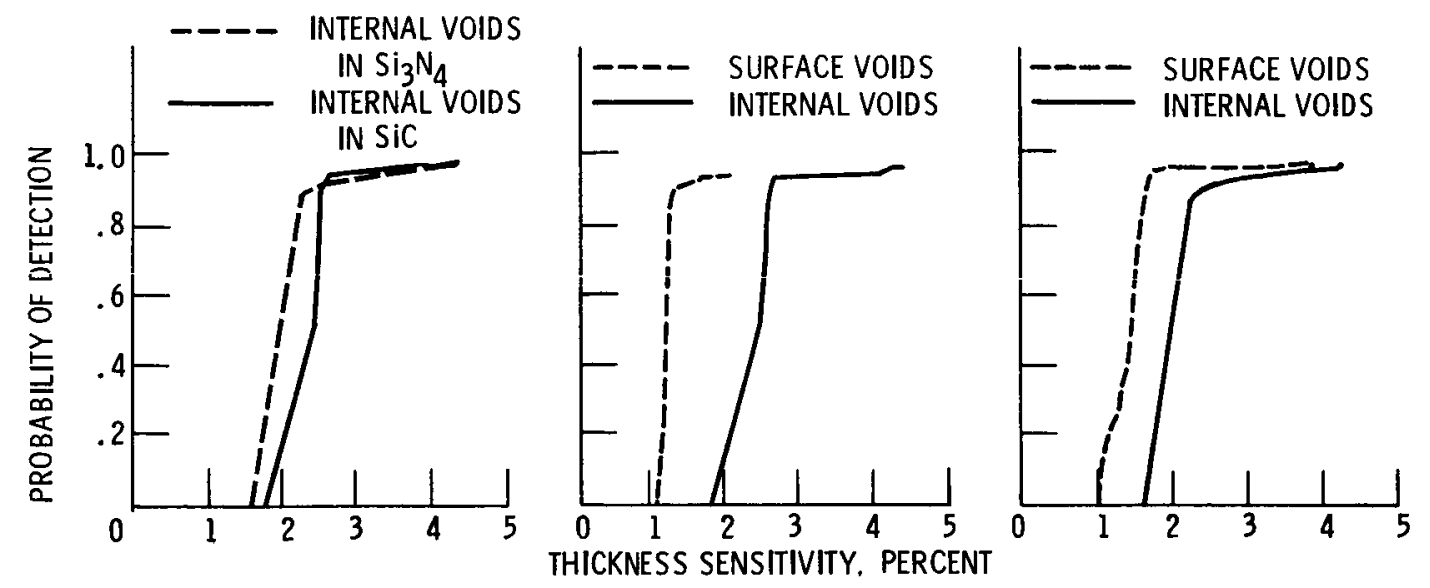

(a) Green SiC and $\mathrm{Si}_{3} \mathrm{~N}_{4}{ }^{*}$

(b) Green SiC.

(c) Green $\mathrm{Si}_{3} \mathrm{~N}_{4}$.

Figure 5. - Lower bound probability-of-detection of surface and internal voids in green isopressed SiC and $\mathrm{Si}_{3} \mathrm{~N}_{4}$ bars by microfocus $\mathrm{x}$-ray. Thickness sensitivity in percent equals 100 tvoid dimension in $x$-ray beam direction)//thickness of specimen in same direction). Probability of detection calculated at 0.95 confidence level. 


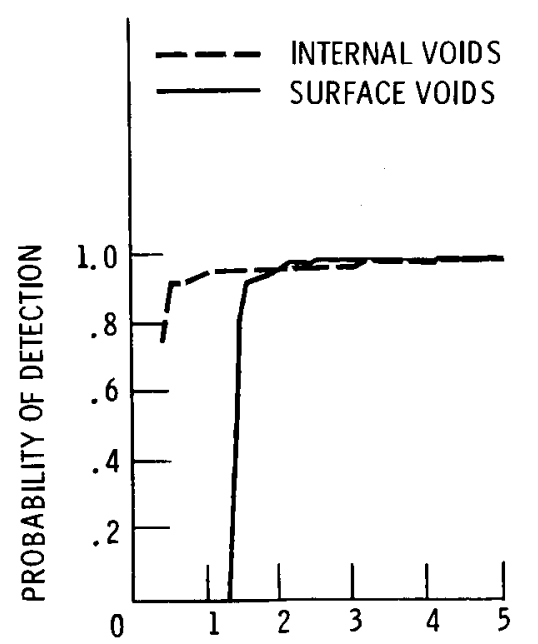

(a) Sintered $\mathrm{Si}_{3} \mathrm{~N}_{4}$.

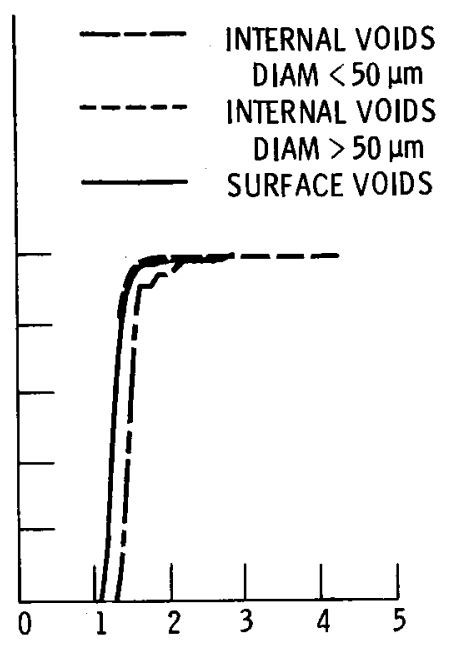

(b) Sintered SiC.

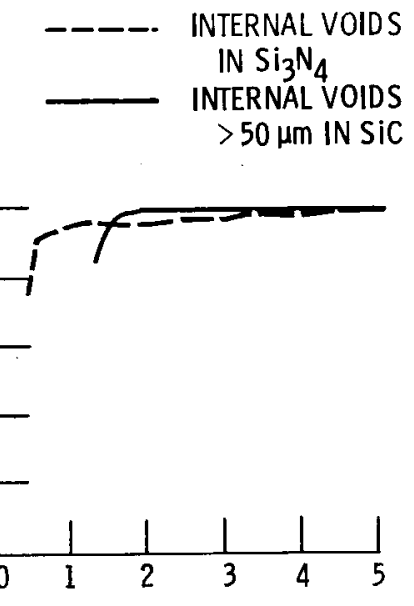

(c) Sintered $\mathrm{SiC}$ and $\mathrm{Si}_{3} \mathrm{~N}_{4}$.

Figure 6. - Lower bound probability-of-detection of surface and internal voids in sintered $\mathrm{SiC}$ and $\mathrm{Si}_{3} \mathrm{~N}_{4}$ bars by microfocus $x$-ray. Thickness sensitivity in percent equals 100 (void dimension in x-ray beam direction)/(thickness of specimen in same direction). Probability of detection calculated at 0.95 confidence level.

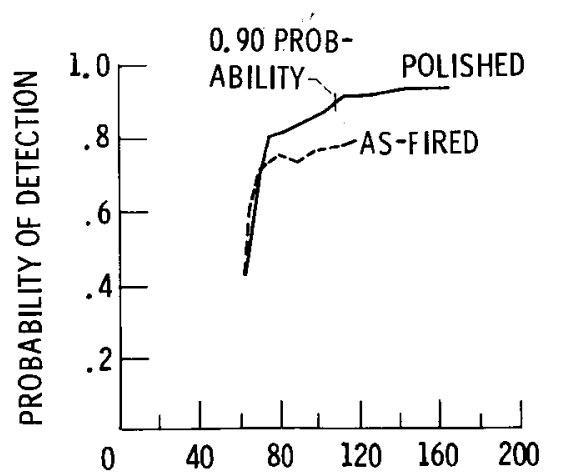

(a) Specimen thickness, $2 \mathrm{~mm}$.

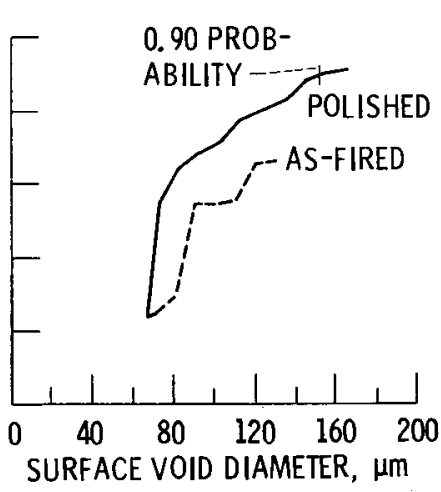

(b) Specimen thickness, $3 \mathrm{~mm}$.

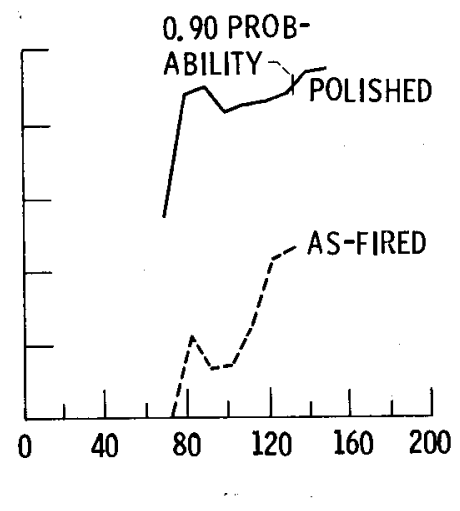

(c) Specimen thickness, $4 \mathrm{~mm}$.

Figure 7. - Effect of specimen thickness and surface condition on probability-of-detection of surface voids by SLAM in sintered silicon nitride. Effect of thickness is evident only for specimens with as-fired surfaces. Probability of detection calculated at 0.95 confidence level. 


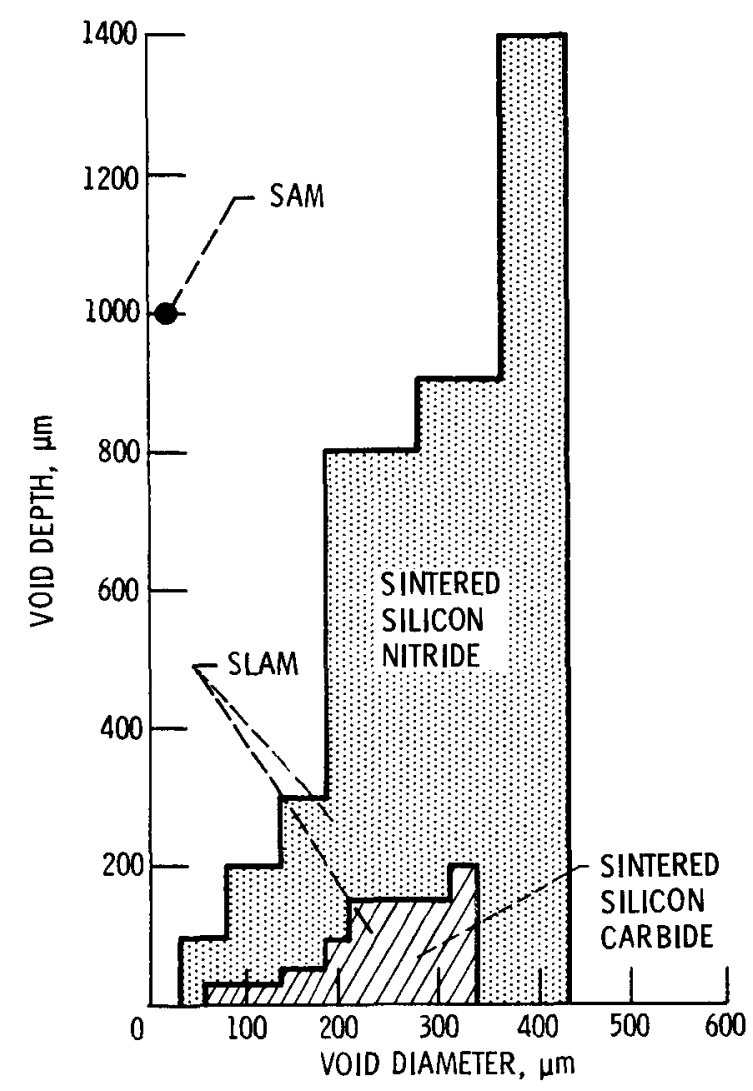

Figure 8 - Effect of void depth, void diameter, and matrix material on probability-of-detection of internal voids by scanning laser acoustic microscopy (SLAM) and scanning acoustic microscopy (SAM). Probability of detection was 0.90 at 0.95 confidence level. 
SEM ENCLOSURE

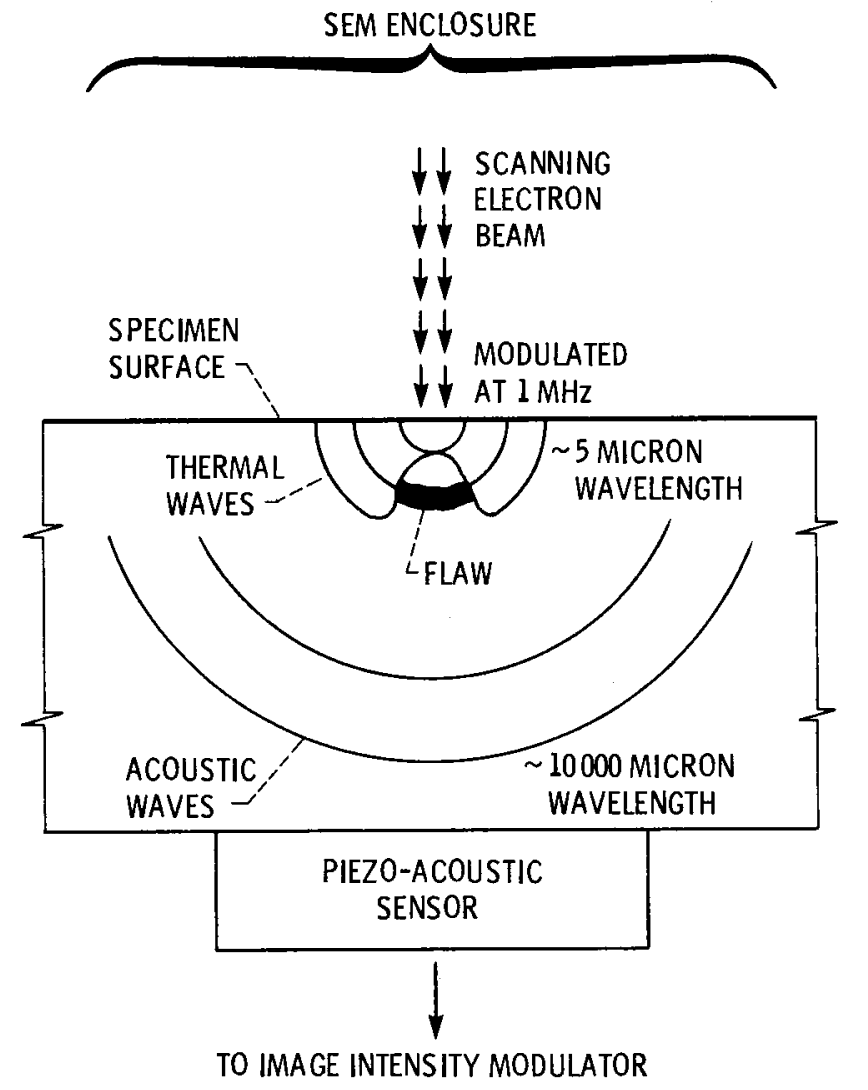

Figure 9. - Schematic representation of a thermo-acoustic device utilizing an electron beam source and an ultrasonic sensor housed in a scanning electron microscope enclosure. 


\section{ORIGINAL PACE IS \\ OF POOR QUALITY}

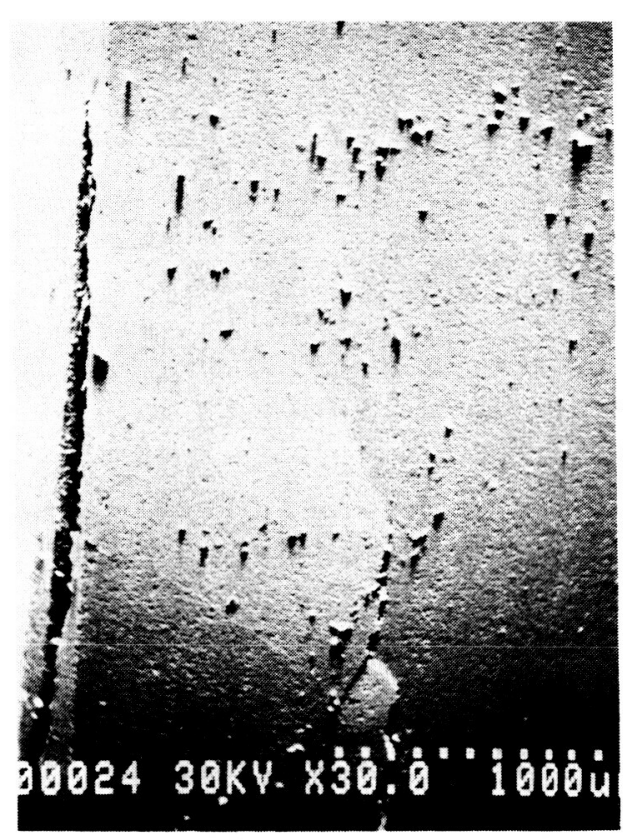

(a) SEM backscatter image.

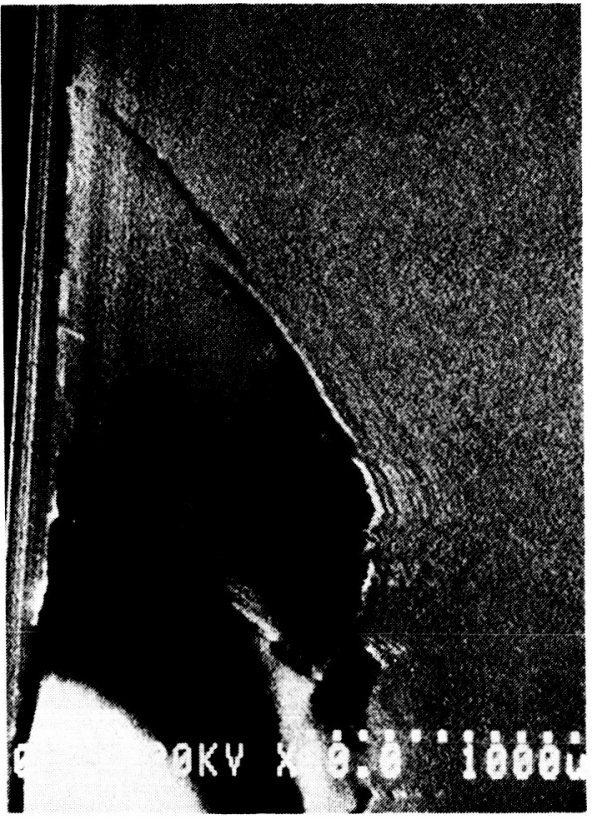

(b) SEAM image.

Figure 10. - Images of a spall crack near the edge of a silicon carbide MOR bar obtained by a conventional SEM technique and by scanning electron acoustic microscopy (SEAM). SEAM reveals subsurface cracking not shown by SEM. Dust visible in the SEM image was ignored by SEAM.

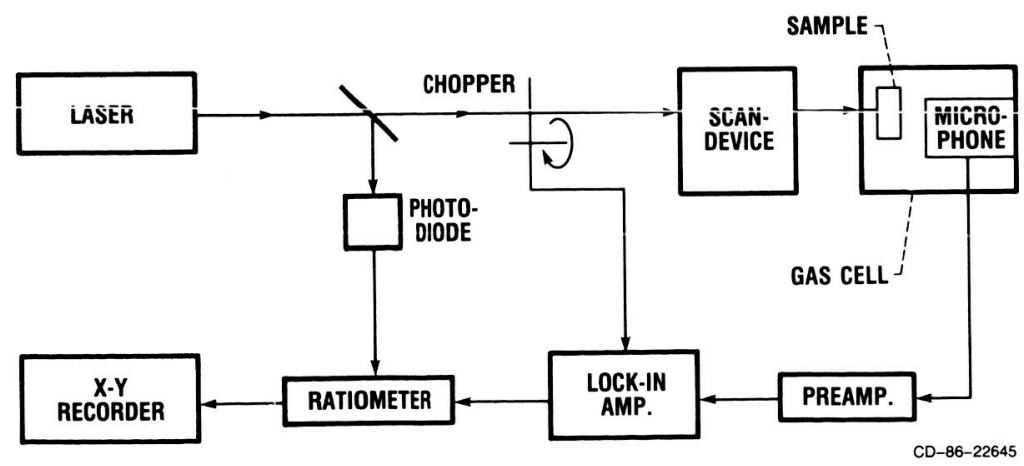

Figure 11 - Block diagram of a photoacoustic microscopy (PAM) system utilizing a laser heating source and a gas filled specimen isolation cell. 


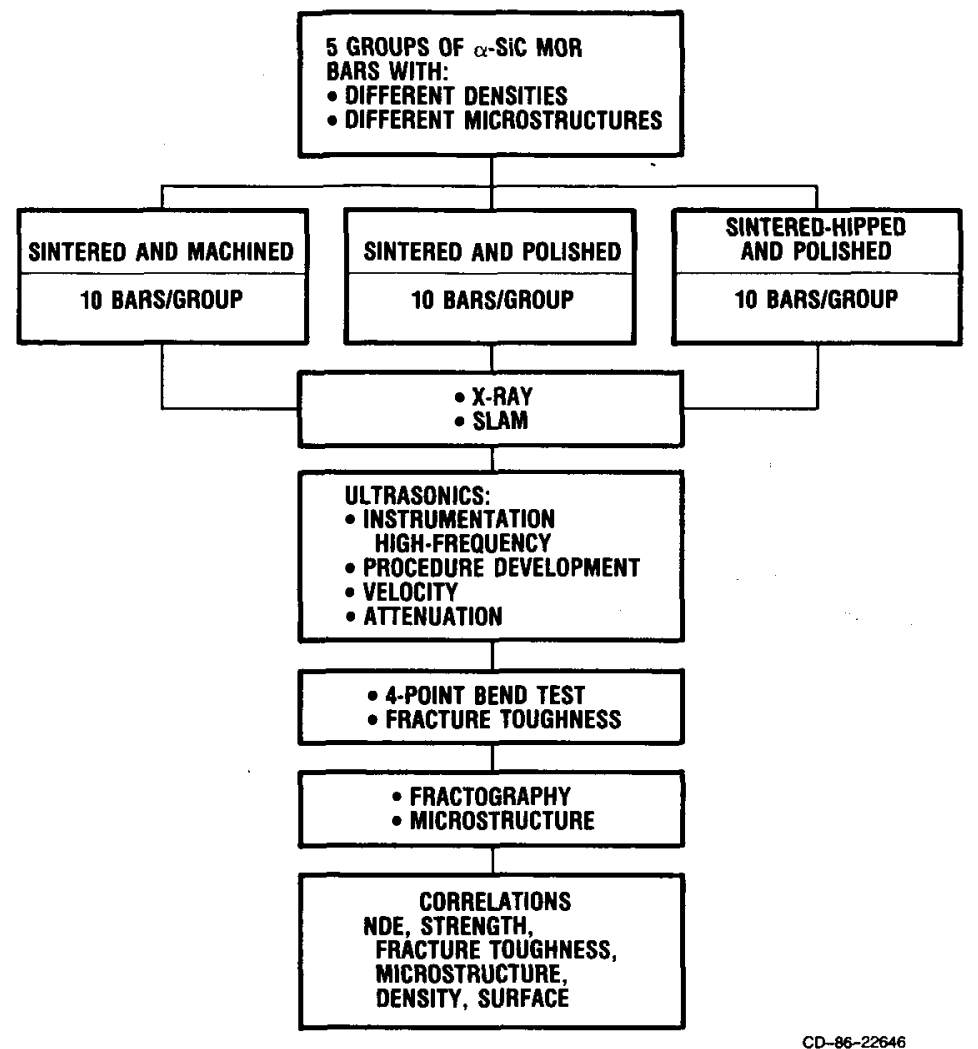

Figure 12 - Flow chart of program to study applicability of NDE for characterizing ceramic microstructure, surface finish, and effects on strength. 


\begin{tabular}{|c|c|c|c|}
\hline 2. Government Accession & 2. Government Accession No. & \multicolumn{2}{|l|}{ 3. Recipient's Catalog No. } \\
\hline \multirow{2}{*}{\multicolumn{2}{|c|}{$\begin{array}{l}\text { 4. Title and Subtitle } \\
\text { Nondestructive Evaluation of Structural Ceramics }\end{array}$}} & \multicolumn{2}{|l|}{ 5. Report Date } \\
\hline & & \multicolumn{2}{|c|}{$\begin{array}{l}\text { 6. Performing Organization Code } \\
533-05-01\end{array}$} \\
\hline \multirow{3}{*}{\multicolumn{2}{|c|}{$\begin{array}{l}\text { 7. Author(s) } \\
\text { Stanley J. Klima, George Y. Baaklint, and } \\
\text { Phillip B. Abel }\end{array}$}} & \multirow{2}{*}{\multicolumn{2}{|c|}{$\begin{array}{l}\text { 8. Performing Organization Report No. } \\
\text { E-3446 }\end{array}$}} \\
\hline & & & \\
\hline & & \multicolumn{2}{|l|}{ 10. Work Unit No. } \\
\hline \multirow{2}{*}{\multicolumn{2}{|c|}{$\begin{array}{l}\text { 9. Performing Organization Name and Address } \\
\text { National Aeronautics and Space Administration } \\
\text { Lewis Research Center } \\
\text { Cleveland, Ohio } 44735\end{array}$}} & \multirow{2}{*}{\multicolumn{2}{|c|}{ 11. Contract or Grant No. }} \\
\hline & & & \\
\hline \multirow{2}{*}{\multicolumn{2}{|c|}{$\begin{array}{l}\text { 12. Sponsoring Agency Name and Address } \\
\text { National Aeronautics and Space Administration } \\
\text { Washington, D.C. } 20546\end{array}$}} & \multicolumn{2}{|c|}{$\begin{array}{l}\text { 13. Type of Report and Period Covered } \\
\text { Technical Memorandum }\end{array}$} \\
\hline & & \multicolumn{2}{|c|}{ 14. Sponsoring Agency Code } \\
\hline \multicolumn{4}{|c|}{$\begin{array}{l}\text { 15. Supplementary Notes } \\
\text { Prepared for the Twenty-fourth Automotive Technology Development Contractors' } \\
\text { Coordination Meeting, sponsored by the U.S. Department of Energy, Dearborn, } \\
\text { Michigan, October 27-30, } 1986 \text {. Stanley J. Klima and Phillip B. Abel, NASA Lewis } \\
\text { Research Center; George Y. Baaklini, Cleveland State University, Cleveland, Ohio } \\
44115 \text {. }\end{array}$} \\
\hline \multicolumn{4}{|c|}{$\begin{array}{l}\text { 16. Abstract } \\
\text { A review is presented on research and development of techniques for nondestructive } \\
\text { evaluation and characterization of advanced ceramics for heat engine applica- } \\
\text { tions. Highlighted in this review are Lewis Research Center efforts in micro- } \\
\text { focus radiography, scanning laser acoustic microscopy (SLAM), scanning acoustic } \\
\text { microscopy (SAM), scanning electron acoustic microscopy (SEAM), and photoacoustic } \\
\text { microscopy (PAM). The techniques were evaluated by applying them to research } \\
\text { samples of green and sintered silicon nitride and silicon carbide in the form of } \\
\text { modulus-of-rupture bars containing seeded voids. Probabilities of detection of } \\
\text { voids were determined for diameters as small as } 20 \text { pm for microfocus radiography, } \\
\text { SLAM, and SAM. Strengths and limitations of the techniques for ceramic applica- } \\
\text { tions are identified. Application of ultrasonics for characterizing ceramic } \\
\text { microstructures is also discussed. }\end{array}$} \\
\hline $\begin{array}{l}\text { 17. Key Words (Suggested by Author(s)) } \\
\text { Mondestructive testing; Nondestructive evaluation; } \\
\text { Ultrasonics; Acoustic microscopy; Sonic testing; } \\
\text { Radiography; Microfocus x-ray; NDE; NDI; NDT; } \\
\text { Reliability; Probability of detection; Materials } \\
\text { characterization; Ceramics; Photoacoustic microscopy }\end{array}$ & $\begin{array}{l}\text { 18. Distribu } \\
\text { Unc la } \\
\text { STAR }\end{array}$ & - unlimited & \\
\hline $\begin{array}{l}\text { 19. Security Classif. (of this report) } \\
\text { Unclassiffied }\end{array}$ & page) & 21. No. of pages 18 & 22. Price ${ }^{*} \mathrm{AO2}$ \\
\hline
\end{tabular}

*For sale by the National Technical Information Service, Springfield, Virginia 22161 